\section{The irresistible rise of interprofessional supervision}

\author{
John Launer
}

Interprofessional supervision happens when someone from one profession supervises a colleague from another. This can occur in a single episode - for example, through discussion of an individual case or extend to a long term, regular arrangement. I have been a longstanding advocate and campaigner for supervision across the professions, ${ }^{1}$ and it is gratifying to see that the idea is spreading. In the United Kingdom, for example, some trainees in general practice now have educational supervisors who are nurse practitioners by background. In an increasing number of localities, professionals of all kinds including pharmacists and hospital consultants as well as general practitioners and nurses - are now getting together in collaborative learning groups to discuss case narratives covering a variety of conditions including diabetes and frailty. ${ }^{2}$ In many hospital specialties like midwifery, neonatal medicine, rehabilitation, musculoskeletal medicine and palliative care, senior non-medical professions now have specialised knowledge and experience that closely parallels that of their medical colleagues. This is providing opportunities for doctors to turn to others for supervision, support and case discussions as much as to their own peers.

Some doctors inevitably have fears about interprofessional supervision. This is often because they associate supervision mainly with training and monitoring performance rather than with dialogue and reflection. They may be sceptical about the idea that these functions are inseparable, or could be carried out well by someone without a medical qualification. Doctors may see the increasing use of interprofessional supervision as a route towards providing education on the cheap. They may also have concerns about the risks of losing a clear professional identity, acquiring lower status and less independence, and of increasing control of doctors by non-medical management.

Such fears are all understandable, and should lead to caution about introducing

Correspondence to Dr John Launer, Associate Editor, Postgraduate Medical Journal, London, WC1H 9JP, UK; johnlauner@aol.com interprofessional supervision without adequate thought or for the wrong motives. It is certainly hard to imagine that it could ever entirely replace basic or core training. When it does take place as part of these, supervisors will always need to have a good understanding of the curricula and regulatory frameworks of any other profession they are working with. However, organised properly and with the right precautions, interprofessional supervision can lead to equal benefits both during training and for established clinicians.

\section{SEEING THE BENEFITS}

As an educator, I regularly lead training workshops on interprofessional supervision for practitioners at all levels of experience, and I find that most people accept the idea far more readily now than twenty years ago. In the past week alone, I have led two workshops for primary care networks in different parts of London. Each had the aim of giving people a chance to practise interprofessional supervision and, by doing so, to get to know other colleagues from their own locality better. Participants included general practitioners, nurses, allied health professionals, social workers and managers. As we always do at such workshops, we asked people to come along with 'hot' cases in mind: narratives of encounters at work that were bothering them, whether with patients, colleagues or teams. After a short introduction to the main elements of supervision - including the need to work mainly through questions, and to try and understand the supervisee's work context and career stage as well as the case itself - we gave everyone a chance to practise supervision in a pair with someone from another profession, or to work in a small group with mix of these. Events like these can help people to see the benefits of interprofessional supervision very quickly.

As the participants in these workshops discovered, the first advantage of interprofessional supervision is that it brings entirely new perspectives to one's work. Many of the dilemmas we face from day to day as health professionals, at any level of experience, relate to complex cases involving issues such as communication, relationships at work, ethics and uncertainty. These issues are common to virtually everyone in the health service, regardless of their original training. It often matters far less for supervisors to have similar levels of technical knowledge than to possess generic human skills like empathy, an open mind and a capacity to invite reflection. Sometimes a colleague like a social worker or even a lay manager may be more likely to ask questions of doctors about aspects of a case or encounter that they a doctor had never considered, and hence to stimulate new thinking. ${ }^{3}$

An even stronger argument in favour of interprofessional supervision is that it can encourage a more positive attitude to team working and local professional networks generally. The benefits of multidisciplinary teams on patient care are well known and widely promoted. ${ }^{4}$ So are the advantages of learning alongside other disciplines during basic training and beyond. ${ }^{5}$ In spite of this, true multiprofessional working and training is still proceeding very slowly in many places. Clinicians may pay lip service to it, or even work or learn together in the same physical space, but their interaction can still be confined to the exchange of information, or to making requests or responding to them. Ingrained professional cultures and traditions, ignorance of other ways of working, and the hierarchies of organisations and social class can still stand in the way of truly collaborative working. ${ }^{7}$ All of these factors can inhibit a free exchange of ideas in a team or among local colleagues in the community. Introducing interprofessional supervision in workplaces and localities can help to overcome all these obstacles, by encouraging people to build up trust and greater respect for each other's judgement.

\section{LESSONS FROM RESEARCH}

Research into interprofessional supervision has mostly taken place in mental health or social work settings and has focused on regular ongoing supervision for experienced practitioners. Nevertheless, the findings do have some lessons to offer to medicine at all levels. In a careful review of the literature, Allyson Davys and Liz Beddoe from New Zealand ${ }^{8}$ looked at nine studies and identified all the factors that are currently leading to an increased use of interprofessional supervision. These include changes in management structures, staff having managers from outside their own profession, and membership of multidisciplinary teams 
where supervision crosses professions. An increase may also come about because of relative shortages of properly trained supervisors or, more positively, from practitioners actively selecting supervisors from outside their own field because of the new perspectives they bring.

The research review also provided confirmation of the advantages of interprofessional supervision. One of these is the direct acquisition of skills and knowledge from other disciplines. An even more important one is awakening to the underlying assumptions of your own practice generally, and thinking more critically about these. Professionals also gain a better understanding and appreciation of the different contributions, perspectives and roles of others. Inevitably, the studies show that interprofessional supervision can also raise challenges. People carrying it out need to address differences in knowledge, values, skills and professional contexts, along with ethical and practice codes, and expected competencies.

Overall, however, Davys and Beddoe conclude that interprofessional supervision 'can offer fresh and rich perspectives, introduce new and different knowledge and skill sets and can challenge the "taken for granted' assumptions which creep into daily practice.' As such, it offers an important, and probably essential counterpart to supervision from within our own profession. It should become an integral component of multiprofessional collaboration and local healthcare networks.

Funding The authors have not declared a specific grant for this research from any funding agency in the public, commercial or not-for-profit sectors.

Competing interests None declared.

Patient consent Not required.

Provenance and peer review Not commissioned; internally peer reviewed.

(c) Author(s) (or their employer(s)) 2018. No commercial re-use. See rights and permissions. Published by BMJ.

\section{Check for updates}

To cite Launer J. Postgrad Med J 2018;94:481-482.

Postgrad Med J 2018;94:481-482.

doi:10.1136/postgradmedj-2018-135988

\section{REFERENCES}

1 Launer J. Narrative-based practice in health and social care: conversations inviting change. Abingdon: Routledge, 2018.

2 Launer J. Collaborative learning groups. Postgrad Med J 2015;91:473-4.

3 Scaife J. Supervision in clinical practice: a practitioner's guide. 2nd edn. London: Routledge, 2009

4 Academy of Medical Royal Colleges. Joint Professions' Statement. London: AoMRC. $2017 \mathrm{http}: / / \mathrm{www}$. aomrc.org.uk/statements/joint-professions-statement/ (accessed 30 June 2018).

5 Buring SM, Bhushan A, Broeseker A, et al. Interprofessional education: definitions, student competencies, and guidelines for implementation. Am J Pharm Educ 2009;73:59-8.

6 Freeth D. Interprofessional education. Swanwick T, ed. Understanding medical education: evidence, theory and practice. 2nd edn. London: Wiley-Blackwell, 2013:81-92

7 Liberati EG, Gorli M, Scaratti G. Invisible walls within multidisciplinary teams: Disciplinary boundaries and their effects on integrated care. Soc Sci Med 2016;150:31-9.

8 Davys A, Beddoe L. Interprofessional supervision: opportunities and challenges. Bostock L, ed. Interprofessional staff supervision in adult health and social care services. Brighton: Pavilion Publishing, 2015:37-41. 